\title{
Letter to the Editor: About the Inheritance of the Aryl Sulfatase A
}

\author{
J. ZLOTOGORA, ${ }^{(5)}$ T. COHEN, E. ELIAN, AND G. BACH \\ Department of Human Genetics, Hadassah-Hebrew University Medical Center, Jerusalem, Israel [J. Z., T. C., G. B.], \\ and Department of Pediatrics, Sackler School of Medicine, Tel-Aviv University, Hasharon Hospital, Petah Tiqva, \\ Israel [E. E.]
}

Kihara et al. (2) described recently the possibility of prenatal diagnosis of late infantile metachromatic leukodystrophy (MLD) in a fetus whose mother was affected with pseudo arylsulfatase $\mathbf{A}$ deficiency by the cerebroside sulfate loading test. In this report, the authors discussed several hypotheses which could explain the genetic basis of pseudodeficiency (PD) and concluded in favor of the theory of Langenbeck $e t$ al. (3), "occurrence of another allele for the structural gene of Aryl Sulfatase A (ASA) which codes for enzyme with reduced activity." This theory implies that pseudodeficient individuals carry both the MLD and the PD alleles and are mixed heterozygotes MLD/PD; accordingly there exist two types of heterozygotes with a similar intermediate range of ASA sibs of the pseudodeficient individuals were affected with MLD.

Kihara et al. (2) cited in their report eight families in which at least one individual was pseudodeficient. In one of these families, described by Butterworth et al. (1), the parents of the pseudodeficient individual were tested and had ASA levels within the heterozygous range. This family and our two families are compatible with PD-MLD allelism. To understand better the inheritance of ASA levels and to delineate the different genotypes, we are at present studying an isolate with a high incidence of MLD (4).

Please Note: Response to this letter was published in the July 1980 issue.

Table 1. Arylsulfatase A activity in leukocytes of the parents of two pseudodeficient individuals

\begin{tabular}{|c|c|c|c|}
\hline \multirow[b]{2}{*}{ Individuals } & \multicolumn{3}{|c|}{ ASA activity ${ }^{1}$} \\
\hline & Family 1 & & Family 2 \\
\hline Pseudodeficient individual & 10 & & $15^{2}$ \\
\hline Mother & 60 & & 86 \\
\hline Father & 30 & & 113 \\
\hline \multicolumn{4}{|l|}{ Controls $(n=30)$} \\
\hline Mean & & $186 \pm 49$ (S.D.) & \\
\hline Range & & $95-292$ & \\
\hline \multicolumn{4}{|c|}{ Obligatory heterozygotes $(n=7)^{3}$} \\
\hline Mean & & $63 \pm 28$ (S.D.) & \\
\hline Range & & $31-116$ & \\
\hline \multicolumn{4}{|c|}{ Late infantile MLD patients $(n=5)$} \\
\hline Range & & $0-20$ & \\
\hline
\end{tabular}

\footnotetext{
' Activities expressed as nmoles of substrate hydrolyzed per hr per mg protein and determined as previously described (4).

${ }^{2}$ ASA activity in this case was also determined in cultured skin fibroblasts and was found in the homozygous affected range.

${ }^{3}$ Parents of children with late infantile MLD.
}

activity, the classical MLD heterozygote and the other carrying one PD allele.

Consequently, one parent of pseudodeficient individuals should be a carrier of the MLD allele and the other a carrier of the PD allele, and thus, both should have intermediate ASA activities. This prediction was confirmed by ASA activity determinations of peripheral white blood cells in parents of two unrelated pseudodeficient individuals.

The first case is a normal adult female whose father is an obligate carrier of the MLD allele because he was the progenitor, by a second marriage, of three children affected with late infantile MLD. The second individual is the healthy mother of a child affected with late infantile MLD. The ASA levels of the pseudodeficient women and their parents are summarized in Table 1. No

\section{REFERENCES AND NOTES}

I. Butterworth. J., Broadhead. D. M., and Keay. A. J.: Low arylsulfatase A activity in a family without metachromatic leukodystrophy. Clin. Genet., 14: 213 (1978).

2. Kihara, H., Ho, Chen-Kung, Fluharty, A. L., Tsay, K. K., and Harlage, P. L. Prenatal diagnosis of metachromatic leukodystrophy in a family with pseudo arylsulfatase $A$ deficiency by the cerebroside sulfate loading test. Pediatr. Res., 14: 224 (1980).

3. Langenbeck. U., Dunker, P., Heipertz, R., and Pilz, H.: Inheritance of metachromatic leukodystrophy. Am. J. Hum. Genet., 29: 639 (1977).

4. Zlotogora, J., Bach, G., Barak, Y., and Elian, E.: Metachromatic leukodystrophy in the Habbanite Jews: high frequency in a genetic isolate and screening for heterozygotes. Am. J. Hum. Genet. (in press).

5. Requests for reprints should be addressed to: Dr. Joel Zlotogora. Department of Human Genetics. Hadassah Medical Organization, POB 12000, IL-91 120 Jerusalem, Israel. 